\title{
Tumor Greater Than or Equal to 2.1 Centimeters
}

National Cancer Institute

\section{Source}

National Cancer Institute. Tumor Greater Than or Equal to 2.1 Centimeters. NCI

Thesaurus. Code C120286.

A tumor where the greatest dimension is greater than or equal to 2.1 centimeters. 